\title{
Research Grant Applications to the National Institutes of Health in the Area of Pediatric Nephrology-An Update
}

\author{
ANTONIA C. NOVELLO \\ National Institute of Child Health and Human Development, National Institutes of Health, Bethesda, \\ Maryland 20892
}

In 1980, the American Society of Pediatric Nephrology requested data from the Division of Research Grants (DRG) in order to evaluate the fate of pediatric nephrology grant applications submitted to the NIH. The Pediatric Nephrology Council was concerned that only a small number of pediatric nephrologists were actively engaged in research. This was thought to be due either to the absence of a pediatric study section or the lack of adequate pediatric representation in current study sections. The response to the request for data by the American Society of Pediatric Nephrology Council was published in Pediatric Research 1985. The data covering the period of May 1980 to January 1984 showed an increase in the number of approved pediatric nephrology applications. Although the numbers were too small to warrant statistical evaluation, the pediatric nephrologist applicants were as successful as their adult nephrologist counterparts. In contrast to the prevailing belief, the problem did not reside in the review process, but in the submission rate of applications by pediatric nephrologists. The latter was quite low, but the approval rate was comparable to that for grants in other disciplines. Thus, the data suggested that reorganization of existing study sections or creation of a new one would not remedy the problem addressed by the Pediatric Nephrology Council.

Since January 1984, when this analysis was completed, the number of competing research project grant applications ${ }^{1}$ for all of NIH has risen from 16,798 in FY 1983 to 18,675 in FY 1985 , with the number of approved applications matching this trend14,479 in FY 1983 to 16,763 in FY 1985. In order to assess whether the pediatric nephrology community of investigators was part of this 5-yr trend, the previous data were examined, with the addition of FY 1984 and FY 1985 data through the January 1986 Council.

This 5-yr retrospective data analysis included all proposals related to pediatric nephrology submitted to the NIH as part of the National Institute of Arthritis, Diabetes, and Digestive and Kidney Diseases (NIADDK), rather than only those reviewed by the 10 study sections most frequently involved in the review of pediatric nephrology applications, as was done in the 1985 report. The present approach was thought to yield a more comprehensive analysis of the fate of pediatric nephrology research at the NIH over the last 5 yr. We also looked at the M.D/Ph.D. ratios of the pediatric nephrology community and at five disciplinary categories within the field. All research project applications assigned to the DRG from May 1980 until January 1986 were

Received June 9, 1986; accepted June 19, 1986

Reprints, Antonia C. Novello, M.D., M.P.H., Captain, U. S. Public Health Service, Clinical Professor, Pediatrics, Georgetown University Hospital, Deputy Director, National Institute of Child Health and Human Development, National Institutes of Health, Bethesda, MD 20892.

'RO1, PO1. R23, R43, R44, and U01 projects. R01 = Research Project (traditional); $\mathrm{PO} 1=$ Research Program Projects; R23 = New Investigator Research Award; R43, R44 = Small Business Innovation Research Grants; U01 = Cooperative Agreements. evaluated, including all those reviewed by special study sections. The review included traditional research projects (R01's), New Investigator Research Awards (R23's), and career development awards (K04). Training grants (T32's), fellowships (F32's), clinical investigator awards (K08's), and program projects (P01's) were not considered, nor were grants reviewed by the review section of NIADDK.

The time selected was $5 \mathrm{yr}$ and included data from Council meetings from May 1980 through January 1986. As before, data on the applications were obtained from the open-pending files of the Information for Management, Planning, Analysis and Coordination (IMPAC) System, and the description of each application, the hospital and departmental identification, and special NIADDK renal coding were individually checked to ensure accuracy. All applications to the study sections of the DRG were assessed for the total number of nephrology applications, the total number of pediatric nephrology as a subdivision of the latter, grant mechanisms utilized, their approval and award rate, their revision and award rate, and the award rate of pediatric nephrology as compared to total NIH applications.

\section{RESULTS}

In this combined data analysis it can be seen that despite the increasing volume of competing research grant applications to the NIH in the last $5 \mathrm{yr}$, the DRG study sections have managed not to lose sight of small but important areas of biomedical research. The total number of competing research project applications in the area of nephrology in the last $5 \mathrm{yr}$ has averaged more than 300 applications per year (Table 1). The data show that kidney-related applications make up less than $2 \%$ of all $\mathrm{NIH}$ applications, but constitute a significant portion (11\% or more) of the application assigned to NIADDK's extramural programs (Table 1). Pediatric nephrology, as a subset of total nephrology, however, represents less than $1.7 \%$ of NIADDKs renal applications, less than $0.2 \%$ of all NIH applications, and less than $13 \%$ of the total number of nephrology applications.

Looking at the original data (Table 2), it can be seen that when pediatric nephrology data on 10 Study Sections are incorporated into the total DRG submission rate (Table 3), there is only an increase of 12 pediatric nephrology proposals versus 293 total nephrology proposals, with nine of the former recommended for approval and four actually funded. The percentage of those recommended for approval for the same time period (Tables 4 and 5) increased from $70 \%$ in 1980 to $84 \%$ in 1983 , with a peak in 1982 of $89 \%$. Similarly, the percent of funded applications increased from $32 \%$ in 1980 to $38 \%$ in 1983 , with a dip in the award rate to $26 \%$ in 1981 . In the last 2 yr (FY 1984 and FY 1985), 66 pediatric nephrology proposals were submitted to NIH, of which 60 were approved, six disapproved, and 19 funded.

The approval rate of the last 2 FYs has increased from 85 to 
Table 1. No. of NIH competing research project applications* (May 1980-January 1986 Review Cycles)

\begin{tabular}{|c|c|c|c|c|c|c|}
\hline \multirow[b]{2}{*}{ Review cycle } & \multirow[b]{2}{*}{$\begin{array}{l}\mathrm{NIH} \\
\text { total }\end{array}$} & \multirow[b]{2}{*}{$\begin{array}{l}\text { NIADDK } \\
\text { total }\end{array}$} & \multicolumn{2}{|c|}{$\begin{array}{c}\text { Kidney and related } \\
\text { diseases } \dagger\end{array}$} & \multicolumn{2}{|c|}{$\begin{array}{l}\text { Kidney and related } \\
\text { diseases* as a \% of: }\end{array}$} \\
\hline & & & Total & Pediatrics & $\begin{array}{l}\mathrm{NIH} \\
\text { total }\end{array}$ & NIADDK \\
\hline May 1980-January 1981 & 16,286 & 2098 & 282 & 27 & 1.7 & 13.4 \\
\hline May 1981-January 1982 & 17,871 & 2339 & 310 & 24 & 1.7 & 13.3 \\
\hline May 1982-January 1983 & 17,839 & 2279 & 355 & 37 & 2.0 & 15.6 \\
\hline May 1983-January 1984 & 17,044 & 2314 & 301 & 38 & 1.8 & 13.0 \\
\hline May 1984-January 1985 & 18,825 & 2479 & 322 & 42 & 1.7 & 13.0 \\
\hline May $1985-J a n u a r y ~ 1986$ & 20,630 & 2760 & 311 & 24 & 1.5 & 11.2 \\
\hline
\end{tabular}

* R01, R23, P01 activities.

$\uparrow$ NIADDK.

Table 2. Pediatric nephrology grant applications

\begin{tabular}{|c|c|c|c|c|c|c|c|c|c|c|c|}
\hline \multirow[b]{3}{*}{$F Y$} & \multirow{3}{*}{$\begin{array}{l}\text { No. of } \\
\text { applications } \\
\text { (10 DRG } \\
\text { SS) }\end{array}$} & \multirow{2}{*}{\multicolumn{2}{|c|}{$\begin{array}{l}\text { Nephrology } \\
\text { applications }\end{array}$}} & \multirow{2}{*}{\multicolumn{2}{|c|}{$\begin{array}{c}\text { Pediatric } \\
\text { nephrology } \\
\text { appli- } \\
\text { cations }\end{array}$}} & \multicolumn{5}{|c|}{ Pediatric nephrology applications } & \multirow{3}{*}{$\begin{array}{c}\text { All NIH } \\
\text { funded, average } \\
\text { priority score }\end{array}$} \\
\hline & & & & & & \multicolumn{2}{|c|}{$\begin{array}{l}\text { Recom- } \\
\text { mended }\end{array}$} & \multicolumn{2}{|c|}{ Funded } & \multirow{2}{*}{$\begin{array}{c}\text { Funded, average } \\
\text { priority score }\end{array}$} & \\
\hline & & $n$ & $\% *$ & $n$ & $\% \dagger$ & $n$ & $\%$ & $n$ & $\% \ddagger$ & & \\
\hline 1980 & 2,449 & 229 & 9 & 22 & 0.9 & 15 & 68 & 6 & 40 & 187 & 176 \\
\hline 1981 & 2,371 & 236 & 10 & 24 & 1.0 & 19 & 79 & 5 & 26 & 158 & 169 \\
\hline 1982 & 2,259 & 269 & 12 & 31 & 1.0 & 28 & 90 & 12 & 43 & 162 & 160 \\
\hline 1983 & 2,127 & 221 & 10 & 37 & 1.7 & 32 & 86 & 8 & 25 & 167 & 158 \\
\hline
\end{tabular}

* Based on total number of applications reviewed by the 10 DRG study sections.

$\dagger$ Pediatric nephrology applications reviewed as a percent of all applications reviewed by 10 study sections.

$\ddagger$ Based on the number of pediatric nephrology applications recommended for approval.

Table 3. Pediatric nephrology research project applications (May 1980-January 1984 Review Cycles)

\begin{tabular}{|c|c|c|c|c|c|}
\hline Review cycles & Nephrology* & Pediatric nephrology $\dagger$ & Approved & Disapproved & Fundedf \\
\hline May 1980-January 1981 & 282 & 27 & 19 & 7 & 6 \\
\hline 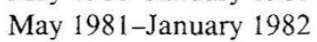 & 310 & 24 & 19 & 5 & 5 \\
\hline May $1982-J a n u a r y ~ 1983$ & 355 & 37 & 33 & 4 & 12 \\
\hline May 1983-January 1984 & 301 & 38 & 32 & 5 & 12 \\
\hline Total & 1248 & 126 & 103 & 21 & 35 \\
\hline
\end{tabular}

* Based on total number of applications reviewed by DRG.

$\dagger$ Pediatric nephrology applications reviewed as a percent of all applications reviewed by DRG.

$\ddagger$ Based on the number of pediatric nephrology applications recommended for approval.

Table 4. Pediatric nephrology grant applications

\begin{tabular}{|c|c|c|c|c|c|c|c|c|c|}
\hline \multirow[b]{2}{*}{ Review cycle } & \multirow{2}{*}{$\begin{array}{c}\text { No. of applications } \\
\text { DRG/NIH }\end{array}$} & \multicolumn{2}{|c|}{ Nephrology } & \multicolumn{2}{|c|}{$\begin{array}{l}\text { Pediatric } \\
\text { nephrology }\end{array}$} & \multicolumn{2}{|c|}{$\begin{array}{l}\text { Recom- } \\
\text { mended for } \\
\text { approval }\end{array}$} & \multicolumn{2}{|c|}{ Funded } \\
\hline & & $n$ & $\%$ & $n$ & $\%$ & $n$ & $\%$ & $n$ & $\%$ \\
\hline May 1980-January 1981 & 16286 & 282 & 1.7 & 27 & 0.1 & 19 & 70 & 6 & 32 \\
\hline May 1981-January 1982 & 17,871 & 310 & 1.7 & 24 & 0.1 & 19 & 79 & 5 & 26 \\
\hline May 1982-January 1983 & 17,839 & 355 & 2.0 & 37 & 0.2 & 33 & 89 & 12 & 36 \\
\hline May 1983-January 1984 & 17,044 & 301 & 1.8 & 38 & 0.2 & 32 & 85 & 12 & 38 \\
\hline May 1984-January 1985 & 18,825 & 322 & 1.7 & 42 & 0.2 & 37 & 88 & 14 & 38 \\
\hline May 1985-January 1986 & 20,630 & 311 & 1.5 & 24 & 0.1 & 23 & 96 & $5^{*}$ & 22 \\
\hline
\end{tabular}

* Preliminary FY 1986 data.

$96 \%$ and the award rate has remained stable at $38 \%$, with a drop to $22 \%$ in January 1986 (the latter figure may represent an incomplete 1986 award rate). The approval and award rates for pediatric nephrology as a whole in the last $2 \mathrm{yr}(38 \%)$ are comparable to those in adult nephrology $(37 \%)$, all NIADDK (39\%), and NIH (37\%). In the last year (up to January 1985) the award rate was better than for NIADDK (38 versus $35 \%$ ), all of $\mathrm{NIH}$, and for adult nephrology (Table 5). Thus, the fate of pediatric applications is certainly no worse than that of applications to NIADDK or to the NIH as a whole.

As might be expected in pediatric nephrology (as in adult renal and related diseases), applicants holding the M.D. degree pre- 
dominate in all the years examined in this report (Table 6). This is in contrast to the NIH as a whole, where about $68 \%$ of the scientists hold the $\mathrm{Ph} . \mathrm{D}$. degree, and to other medically significant areas of research (e.g. bone and mineral metabolism) where
Ph.D. applicants have increased from 56 to $64 \%$ during the same period of time.

Looking at the updated data, it became apparent that pediatric nephrologists in recent years (January 1984-January 1986) were

Table 5. Recommended for approval and award rates for NIH competing research project applications (May 1980-January 1986

\begin{tabular}{|c|c|c|c|c|c|c|c|c|c|}
\hline \multirow[b]{3}{*}{ Review cycles } & \multicolumn{2}{|c|}{$\begin{array}{l}\text { Total kidney and } \\
\text { related diseases } \dagger\end{array}$} & \multicolumn{2}{|c|}{$\begin{array}{c}\text { Pediatric } \\
\text { nephrology } \dagger\end{array}$} & \multirow{3}{*}{$\begin{array}{c}\text { Fiscal } \\
\text { Year }\end{array}$} & \multicolumn{2}{|c|}{ NIADDK total } & \multicolumn{2}{|c|}{$\mathrm{NIH}$} \\
\hline & Approval & Award $\ddagger$ & Approval & Awardț & & Approval & Award $\ddagger$ & Approval & Award \\
\hline & $\%$ & $\%$ & $\%$ & $\%$ & & $\%$ & $\%$ & $\%$ & $\%$ \\
\hline May 1980-January 1981 & 76 & 40 & 70 & 32 & 1981 & 85 & 41 & 82 & 39 \\
\hline May 1981-January 1982 & 79 & 34 & 79 & 26 & 1982 & 87 & 33 & 85 & 35 \\
\hline May 1982-January 1983 & 88 & 30 & 89 & 36 & 1983 & 90 & 39 & 86 & 37 \\
\hline May 1983-January 1984 & 89 & 36 & 84 & 38 & 1984 & 90 & 39 & 87 & 37 \\
\hline May 1984-January 1985 & 91 & $37 \S$ & 88 & 38 & 1985 & 91 & 35 & 89 & 37 \\
\hline May 1985-January 1986 & & & & & t availa & & & & \\
\hline
\end{tabular}

* Review cycle groupings and fiscal year data are not comparable.

$\uparrow$ NIADDK.

$\$$ Based on approved applications.

$\S$ Not yet complete (data are as of November 1985).

Table 6. Degrees held by principal investigators with pediatric nephrology* research project applications recommended for approval (May 1980-January 1986 review cycles)

\begin{tabular}{|c|c|c|c|c|c|c|c|c|c|c|}
\hline \multirow[b]{2}{*}{ Review cycles } & \multicolumn{4}{|c|}{ No. of applications $\dagger$} & \multicolumn{3}{|c|}{$\%$ Distribution } & \multicolumn{3}{|c|}{$\begin{array}{c}\text { All NIH research projects } \\
\% \text { distribution }\end{array}$} \\
\hline & Total & MDs & PhDs & Othert & MDs & PhDs & Other & MDs & PhDs & Other \\
\hline May 1980-January 1981 & 27 & 33 & 3 & 1 & 85 & 11 & 4 & 24.4 & 66.4 & 1.9 \\
\hline May 1981-January 1982 & 24 & 19 & 4 & 1 & 79 & 17 & 4 & 23.3 & 66.1 & 3.1 \\
\hline May 1982-January 1983 & 37 & 33 & 4 & 0 & 89 & 11 & 0 & 22.9 & 68.5 & 2.1 \\
\hline May 1983-January 1984 & 38 & 32 & 5 & 1 & 84 & 13 & 3 & 22.4 & 68.6 & 2.2 \\
\hline May 1984-January 1985 & 42 & 32 & 10 & 0 & 76 & 24 & 0 & 21.9 & 68.9 & 1.6 \\
\hline May 1985-January 1986 & 24 & 22 & 2 & 0 & 92 & 8 & 0 & \multicolumn{3}{|c|}{ Not available } \\
\hline
\end{tabular}

*Includes NIADDK R01, R23, and P01 activities.

$\dagger$ Approvals only.

$\ddagger$ Holders of MDs and PhDs and other degrees.

Table 7. Pediatric nephrology research project applications (May 1980-January 1986 review cycles)

\begin{tabular}{lccccccc}
\hline \multicolumn{1}{c}{ Review cycles } & Nephrology & $\begin{array}{c}\text { Pediatric } \\
\text { nephrology }\end{array}$ & Approved & Disapproved & Funded & Revised & Revised funded \\
\hline May 1980-January 1981 & 282 & 27 & 19 & 7 & 6 & 3 & 0 \\
May 1981-January 1982 & 310 & 24 & 19 & 5 & 5 & 3 & 1 \\
May 1982-January 1983 & 355 & 37 & 33 & 4 & 12 & 4 & 7 \\
May 1983-January 1984 & 301 & 38 & 32 & 5 & 12 & 7 & 7 \\
May 1984-January 1985 & 322 & 42 & 36 & 5 & 14 & 3 \\
May 1985-January 1986 & 311 & 24 & 23 & 1 & 5 & 3 \\
Total & 1881 & 192 & 162 & 27 & 54 & 31 \\
\hline
\end{tabular}

Table 8. Pediatric nephrology* research project applications by activity (May 1980-January 1986 review cycles)

\begin{tabular}{|c|c|c|c|c|c|c|c|c|}
\hline \multirow[b]{2}{*}{ Review cycles } & \multicolumn{2}{|c|}{ All activities } & \multicolumn{2}{|c|}{$\begin{array}{l}\text { Traditional } \\
\text { research } \\
\text { project }(\mathrm{R} 01)\end{array}$} & \multicolumn{2}{|c|}{$\begin{array}{l}\text { Traditional } \\
\text { research } \\
\text { project } \\
(2 \mathrm{R} 01)\end{array}$} & \multicolumn{2}{|c|}{$\begin{array}{l}\text { New } \\
\text { investigator } \\
\text { research } \\
\text { (R23) }\end{array}$} \\
\hline & $n$ & $\%$ & $n$ & $\%$ & $n$ & $\%$ & $n$ & $\%$ \\
\hline May 1980-January 1981 & 27 & 100.0 & 16 & 59 & 4 & 15 & 2 & 7 \\
\hline May 1981-January 1982 & 24 & 100.0 & 16 & 67 & 6 & 25 & 1 & 4 \\
\hline May 1982-January 1983 & 37 & 100.0 & 24 & 65 & 7 & 19 & 1 & 3 \\
\hline May 1983-January 1984 & 38 & 100.0 & 24 & 63 & 4 & 11 & 6 & 16 \\
\hline May $1984-J a n u a r y ~ 1985$ & 42 & 100.0 & 25 & 60 & 5 & 12 & 7 & 17 \\
\hline May 1985-January 1986 & 24 & 100.0 & 17 & 71 & 4 & 17 & 2 & 8 \\
\hline
\end{tabular}

* NIADDK. 
revising their applications and succeeding (at least by 50\%) in getting funded (Table 7). Thus, the traditional NIH advice to applicants to respond to the comments in the critique and reapply seems to be well founded.

As previously described, most of the applications processed and reviewed in pediatric nephrology from 1980-1985 have been traditional R01s and their competitive renewals (Table 8). The second most common mechanism utilized has been the New Investigator Research Award. This new finding indicates a positive trend, showing an increased interest by the pediatric nephrology community. Similarly, the competitive renewals, although

Table 9. Pediatric nephrology scientific disciplines, renal research projects (May 1980-January 1986)

\begin{tabular}{l} 
Elements of normal renal function \\
Anatomy \\
Body fluids, volume, composition, and physical chemistry \\
Solvent and solute transport \\
Renal metabolism and biochemistry \\
Renal circulation \\
Glomerular filtration \\
Renal handling of sodium, potassium, phosphate, calcium, magne- \\
sium, urate \\
Acid base balance, ammonia \\
Pathogenesis \\
Acute renal failure \\
Immunology \\
Response to infection \\
Glomerulopathies \\
Renal response to vascular injury \\
Diabetes and related subjects \\
Disorders of stone formation \\
Neoplasia \\
Pathophysiology \\
Hematology \\
Osteodystrophies \\
Hypertension renin-angiotensin, aldosterone \\
Neurological \\
Pharmacology and others \\
Monoclonal antibodies \\
Mathematical modeling \\
Electrophysiology \\
Molecular biology \\
Urology topics \\
Transplant \\
Conservative treatment \\
Treatment of hypertension \\
\hline
\end{tabular}

fewer in number than the original applications, continue to have the highest award rate (39 versus $28 \%$ ) of the pediatric nephrology applications, indicating a sustained interest and vigor in pediatric nephrology research. All other activities, (e.g. K04, $\mathrm{K} 08$ ) continue to be submitted. However, neither their award rate nor their submission rate is comparable to the other two mechanisms of support, except for supplements which fare rather well.

In this current data analysis, an additional parameter was evaluated. Applications were analyzed by subject matter and further classified into five disciplinary categories (Table 9): 1) elements of normal renal function, 2) pathogenesis, 3) pathophysiology, 4) pharmacology, drugs, and 5) management of patient. As shown in Table 10, the first category was by far the largest and fared better than the other four, followed by pathogenesis. Submissions of clinically related proposals have somewhat increased in the last $5 \mathrm{yr}$, although less so than categories 1 and 2 . Since it has not been possible to make precise distinctions between clinical and basic research from the available data and all categories probably contain a number of clinically related proposals, an attempt at identifying clinical versus basic research was made by examining application abstracts, human subject consent forms, aims, and titles. This yielded a further categorical subset labeled "Management of Patient." The results indicate that although the number of clinically related proposals submitted was far smaller than basic research proposals, in most of the last $5 \mathrm{yr}$ the proportion of awards was as large, on the average, as in the previous disciplinary categories. Also, clinically oriented applications in this group had a somewhat greater disapproval rate. The results do indicate, however, in contrast to speculation, that more specialized or basic studies do not necessarily fare better in the NIH peer review process than clinical ones.

In summary, despite an increase in the rate of submission in the field of kidney and related diseases when all DRG study section data are included, the increased number of NIH applications for research in pediatric nephrology observed between 1980 and 1983 has remained stable in the last 2 FYs. Although the numbers as a whole seem larger, the true increase has not been significant enough to warrant statistical evaluation. Several significant trends are clear, however; a steady, albeit small, increase in the submission rate of pediatric nephrology applications in recent years, the simultaneous increase in approval and award rates, and the observation that senior investigators and new investigators alike are applying, competing, and succeeding. The small numbers do not detract from the more important finding that scientists in pediatric nephrology, by becoming aware of their scientific standing at the $\mathrm{NIH}$, have responded by applying, and are succeeding in obtaining biomedical research funds.

Acknowledgments. The author is indebted to Dr. Jerome Green and Gerry O'Rose for revising the manuscript, to Hildegard Topper for editorial assistance, and to Betty Spaugh, Marie Mitchell, and Terry Pezza for typing the manuscript.

Table 10. Action on pediatric nephrology research project applications by discipline (May 1980-January 1986 review cycles)

\begin{tabular}{|c|c|c|c|c|c|}
\hline & \multirow{2}{*}{$\begin{array}{l}\text { No. of grant } \\
\text { applications }\end{array}$} & \multicolumn{2}{|c|}{$\begin{array}{l}\text { Recommended for } \\
\text { approval }\end{array}$} & \multicolumn{2}{|c|}{$\begin{array}{l}\text { No. of approved } \\
\text { applications funded }\end{array}$} \\
\hline & & $n$ & $\%$ & $n$ & $\%$ \\
\hline Renal function & 101 & 95 & 94 & 28 & 30 \\
\hline Pathogenesis & 94 & 84 & 89 & 16 & 19 \\
\hline Pathophysiology & 9 & 8 & 89 & 1 & 13 \\
\hline Pharmacology, drugs & 10 & 7 & 70 & 1 & 14 \\
\hline Patient management & 31 & 24 & 77 & 8 & 33 \\
\hline
\end{tabular}

